\title{
Clustering of Cases of IDDM 2 to 4 Years after Hepatitis B Immunization is Consistent with Clustering after Infections and Progression to IDDM in Autoantibody Positive Individuals
}

\author{
John Barthelow Classen*
}

Classen Immunotherapies Inc., 6517 Montrose Avenue, Baltimore, MD 21212, USA

\begin{abstract}
Background: Previous studies demonstrated clusters of cases of IDDM occurring 24 to 48 months after immunization with the hemophilus, pertussis and combined measles mumps rubella vaccines. Data was analyzed to determine if similar clustering of cases of IDDM occurred after immunization with the hepatitis B vaccine. Methods: Data on the incidence of IDDM from hepatitis B immunized and unimmunized cohorts of children was analyzed for the presence of clusters occurring after hepatitis B immunization. Results: Data from Italy, France, and New Zealand indicated rises in the incidence of IDDM occurred between 24 to 48 months after the introduction of the hepatitis B immunization in young children. Conclusion: Several different vaccines as well as infections with natural mumps virus are followed by clusters of cases of IDDM that occur about 24 to 48 months after immunization. This suggests a similar mechanism of action, possibly the triggering of a progressive autoimmune phenomenon.
\end{abstract}

Keywords: Type 1 diabetes mellitus, vaccines, hepatitis B.

\section{BACKGROUND}

Data from a large prospective clinical trial proved the hemophilus $b$ vaccine causes type 1 , insulin dependent diabetes (IDDM) [1]. Clusters of cases of vaccine induced IDDM occurred starting 36 months after immunization. Clusters of IDDM have also occurred 24 to 48 months following vaccination with several other vaccines including the pertussis and MMR vaccine [2]. The hepatitis $b$ vaccine has been linked to a rise in IDDM in New Zealand [3]. An attempt was made to determine if an rise of IDDM occurred in other areas following the introduction of the hepatitis B vaccine and if the rise was consistent with the clustering seen with other vaccines. A cohort analysis was performed to measure the incidence of in IDDM in vaccinated and unvaccinated cohorts in Italy. The incidence of IDDM in France was compared before and after hepatitis B immunization. A follow up study was also performed on new data from New Zealand.

\section{METHODS}

A cohort analysis was performed to measure the incidence of IDDM in hepatitis B vaccinated and unvaccinated cohorts from Central Italy. Mandatory hepatitis B immunization was implemented in Italy in 1991 and required all children to receive the hepatitis $\mathrm{B}$ vaccine when they turned 3 months old or 12 years of age. No catch-up program was implemented for children between these time frames. Children were given recombinant hepatitis B vaccine. Immunization data on the cohorts was provided by Osservatorio Epidemiologico in Rome. All cases of IDDM occurring in children under age 15 have been recorded in a prospective diabetes

*Address correspondence to this author at the Classen Immunotherapies Inc., 6517 Montrose Avenue, Baltimore, MD 21212, USA; Tel: (410) $377-$ 8526; E-mail: Classen@vaccines.net registry in Rome and the Lazio Region of Italy since 1989 [4]. The registry has an estimated ascertainment of about $85 \%$. Validation of the registry was available for all cases of IDDM occurring before 1999. Population census data on the number of children living in the region for each age was available through The Italian Statistical Year Book.

Medline was searched to locate publications on the incidence of IDDM in children age 0-14 living in western industrialized nations. Key words used in the Medline search were diabetes, insulin and incidence. References listed in papers found on Medline were used to find additional texts on the subject. It was prospectively planned to include only papers on Caucasian populations from Western Europe countries, United States, Canada, Australia, and New Zealand because it was believed that the standards of living and medical care of the Caucasian populations in these countries were similar and our previous studies had revealed an effect in children living in these countries. The search was limited to papers containing incidence data primarily from 1975 to present and containing at least 100 cases of IDDM in the study population. After identifying countries with data meeting the criteria mentioned above. A Medline search was performed to determine if changes in immunization practices hepatitis B, but also with other vaccines including DTP, polio, hepatitis A, chickenpox, measles, mumps and rubella, BCG, influenza, vaccine occurred during the time frame covered by the diabetes registry.

\section{STATISTICS}

Chi square analysis was performed on each strata from Italy. A two strata analysis was performed to determine the probability of both outcomes. The later used a two tailed analysis. Chi Square tests were performed on data from France and New Zealand. Statistics on data from New Zealand were conservatively calculated assuming 105,306 children age 0-19 and a proportional number of children age 0 - 
14, 78,980 children. Statistics were performed using EP-6 program provided by the WHO.

\section{RESULTS}

\section{Italy}

Separate cohort analysis was performed on children who were immunized starting between 2-3 months of life and 12 years of age (Table 1). Since the registry was started in 1989, data was available for only 2 unimmunized births cohorts (1989-1990) from age 0 through age 5. Almost no cases of IDDM occurred before year 1 of life so data was analyzed for 3 cohorts 1988, 1989 and 1990 between age 1 through age 5 . Three vaccinated cohorts were comprised of children born in 1991,1992, and 1993. All cases of IDDM occurring in children between age 5 and 6 in the 1993 cohort have not been identified since some of these are likely to have occurred in 1999. There were approximately 150,000 children in each group. The cumulative incidence of IDDM in the vaccinated and unvaccinated group under 6 was 51 and 41 cases per 100,000 , respectively, with a relative risk of 1.24 $(\mathrm{p}=0.2)$. Data was available for only one birth cohort, 1977, where all the children turned twelve after the registry started but turned 13 before 1991. There was complete data on 7 vaccinated birth cohorts, 1978 through 1984, who turned 12 in 1991 or later. In the cohort of children 12 years of age (vaccinated and unvaccinated) and followed through age 14, the cumulative incidence of Type 1 diabetes was 23 and 10.3 cases/100,000 respectively, with a relative risk of 2.22 $(p=0.036)$. The combined relative risk in this study was 1.4 $(\mathrm{p}=0.039)$.

\section{France}

The French government began promoting routine hepatitis B immunization of all children in 1994. The vaccine was administered to children aged 11 and to infants. Newborn immunization was generally reserved for offspring of hepatitis $B$

Table 1. Incidence of IDDM in Hepatitis B Immunized and Unimmunized Italian Birth Cohorts

\begin{tabular}{|c|c|c|c|c|c|c|c|c|c|}
\hline \multicolumn{10}{|c|}{ Cases of IDDM at specific ages, children immunized at 3 months } \\
\hline \multirow{4}{*}{$\begin{array}{l}\text { Control Birth Cohort } \\
(1988-1990) \\
\text { Hep B Immunized Birth Cohort } \\
(1991-1993)\end{array}$} & \multirow[b]{2}{*}{$\begin{array}{l}\text { Cohort } \\
\text { Size }\end{array}$} & \multicolumn{5}{|c|}{ Age Years } & \multirow[b]{2}{*}{$\begin{array}{l}\text { Total } \\
\text { Cases } \\
\text { IDDM }\end{array}$} & & \\
\hline & & $\begin{array}{c}1 \\
\text { Cases } \\
\text { IDDM }\end{array}$ & $\begin{array}{c}\underline{\mathbf{2}} \\
\text { Cases } \\
\text { IDDM }\end{array}$ & $\begin{array}{c}\underline{\mathbf{3}} \\
\text { Cases } \\
\text { IDDM }\end{array}$ & $\begin{array}{c}\underline{4} \\
\text { Cases } \\
\text { IDDM }\end{array}$ & $\begin{array}{c}\underline{\mathbf{5}} \\
\text { Cases } \\
\text { IDDM }\end{array}$ & & & \\
\hline & 147,671 & 8 & 9 & 17 & 10 & 17 & 61 & & \\
\hline & 150,546 & 11 & 14 & 21 & 12 & 19 & 77 & & \\
\hline $\begin{array}{l}\text { Relative Risk } \\
\text { (Hep B vaccinated/Control) }\end{array}$ & & 1.35 & 1.53 & 1.21 & 1.18 & 1.10 & & $1.24 .88<\mathrm{RR}<1.73$ & $\mathrm{p}=0.212$ \\
\hline \multicolumn{10}{|c|}{ Cases of IDDM at specific ages, children immunized at age 12} \\
\hline & & \multicolumn{4}{|c|}{ Age Years } & & & & \\
\hline & $\begin{array}{l}\text { Cohort } \\
\text { Size }\end{array}$ & $\begin{array}{c}\underline{\mathbf{1 2}} \\
\text { Cases } \\
\text { IDDM }\end{array}$ & $\begin{array}{l}\underline{\mathbf{1 3}} \\
\text { Cases } \\
\text { IDDM }\end{array}$ & $\begin{array}{c}\underline{\mathbf{1 4}} \\
\text { Cases } \\
\text { IDDM }\end{array}$ & & & $\begin{array}{l}\text { Total } \\
\text { Cases } \\
\text { IDDM }\end{array}$ & & \\
\hline $\begin{array}{l}\text { Cotrol Birth Cohort } \\
\text { (1977) }\end{array}$ & 67,584 & 4 & 1 & 2 & & & 7 & & \\
\hline $\begin{array}{l}\text { Hep B Immunized Birth Cohort } \\
(1978-1984)\end{array}$ & 400,078 & 36 & 33 & 23 & & & 92 & & \\
\hline $\begin{array}{l}\text { Relative Risk } \\
\text { (Hep B vaccinated/Control) }\end{array}$ & & 1.5 & 5.6 & 1.9 & & & & $2.221 .03<\mathrm{RR}<4.79$ & $\mathrm{p}=0.036$ \\
\hline Combined weighted relative risk & & & & & & & & $1.41 .02<\mathrm{RR}<1.89$ & $\mathrm{p}=0.039$ \\
\hline
\end{tabular}


Table 2. Incidence of IDDM in France before and after Hepatitis B Immunization

\begin{tabular}{|c|c|c|c|c|c|c|c|c|c|c|}
\hline \multirow{2}{*}{ Year } & \multicolumn{10}{|c|}{ Yearly Incidence, Cases Per 100,000 } \\
\cline { 2 - 22 } & $\mathbf{1 9 8 8}$ & $\mathbf{1 9 8 9}$ & $\mathbf{1 9 9 0}$ & $\mathbf{1 9 9 1}$ & $\mathbf{1 9 9 2}$ & $\mathbf{1 9 9 3}$ & $\mathbf{1 9 9 4}$ & $\mathbf{1 9 9 5}$ & $\mathbf{1 9 9 6}$ & $\mathbf{1 9 9 7}$ \\
\hline \hline Age 15-19 & 6 & 6 & 6 & 7 & 6 & 6 & 7 & 6 & 6 & 6 \\
\hline Age 5-9 & 9 & 7 & 9 & 7 & 10 & 10 & 11 & 12 & 11 & 11 \\
\hline Age 10-14 & 10 & 12 & 11 & 11 & 11 & 13 & 12 & 14 & 14 & 15 \\
\hline Age 0-4 & 4 & 4 & 5 & 4 & 5 & 3 & 5 & 5 & 6 & 7 \\
\hline
\end{tabular}

infected mothers [5]. The incidence of IDDM in parts of France had been recorded in children 0-19 years old between the years 1988 and 1997 [6] (Table 2). The incidence of IDDM was stable in the 0-4 year olds between 1988-1995 and began rising in 1996 reaching an interval maximum in 1997. During the 10 year interval the incidence of IDDM rose from 4.17 (95\% CI: $2.64-5.70)$ cases/100,000 in 1988 to 7.48 (95\% CI :5.63-9.27) cases/100,000 in 1997 (79\% rise). The incidence of IDDM post immunization in 1997, compared to preimmunization 1988 through 1994, indicated an approximate relative risk of $R R 1.61(1.11<R R<2.33)(p=0.01)$. The incidence of IDDM in the 10-14 age groups was stable between 1988 to 1994 and began to rise in 1995 . The incidence reached an interval maximum in 1997. The incidence went from approximately 10.25 cases $/ 100,000$ in 1988 to 14.5 cases/100,000 in 1997 (39\% rise). The incidence of IDDM post immunization in 1997, compared to preimmunization 1988 through 1994, indicated an approximate relative risk of $R R: 1.31(1.04<R R<1.65)(p=0.02)$. By contrast the incidence of IDDM was stable in the 15-19 year old age group. The incidence went from approximately 6 cases/100,000 in 1988 to 5.25 cases/100,000 in 1997. The incidence of IDDM rose modestly in the 5-9 year old age group. The incidence went from approximately 9 cases $/ 100,000$ in 1988 to 11 cases/100,000 in 1997 (22\% rise).

\section{New Zealand}

The hepatitis B immunization program was started in New Zealand in 1988. The vaccine was initially given to all preschool children [7]. The immunization program was soon expanded so that all the children under the age of 16 were offered the vaccine. Data on the incidence of IDDM in the South Island of New Zealand was published in 1992 [8] and revised numbers were published in 2002 [9]. There were 113,694 children age $0-19$ according to the 1981 census and 105,306 according to the 1996 census. The incidence of IDDM was relatively stable between 1980-1989 in both ages 0-14 and 0-19 (Table 3) and the incidence actually declined between 1980-1984 and 1985-1989. By contrast the incidence rose in both ages 0-14 and 0-19 within 2 years after the introduction of the hepatitis $B$ vaccine. In the $0-14$ age group the incidence rose from 15.37 to 22.7 cases $/ 100,000$ between 1980-1989 and 1990-1999 (RR 1.48, 1.17<1.48< $1.86, \mathrm{p}=0.0008)$. In the $0-19$ age group the incidence rose from 14.87 to 20.13 between 1980-1989 and 1990-1999 (RR $1.35,1.1<1.35<1.66, \mathrm{p}=0.004)$.

\section{DISCUSSION}

We previously proved the hemophilus vaccine causes IDDM in children and mice [1]. In a prior report we showed a rise in the incidence of IDDM in New Zealand following a massive hepatitis $B$ vaccine program $[3,10]$. Following the

Table 3. Incidence of IDDM in New Zealand, before and after Hepatitis B Immunization

\begin{tabular}{|c|c|c|}
\hline & Age 0-14 & Age 0-19 \\
\hline \hline Pre Hepatitis B vaccine & Incidence/100,000 & Incidence/100,000 \\
\hline Years & & \\
\hline $1980-1984$ & 17.28 & 15.74 \\
\hline $1985-1989$ & 13.45 & 14 \\
\hline $\mathbf{( 1 9 8 0 - 1 9 8 9 )}$ & $\mathbf{1 5 . 3 7}$ & $\mathbf{1 4 . 8 7}$ \\
\hline Post Hepatitis B Vaccine & Incidence/100,000 & Incidence/100,000 \\
\hline Years & & 18.9 \\
\hline $1990-1994$ & 22.11 & 21.34 \\
\hline $1995-1999$ & 23.43 & $\mathbf{2 0 . 1 3}$ \\
\hline $\mathbf{( 1 9 9 0 - 1 9 9 9 )}$ & $\mathbf{2 2 . 7}$ & 1.35 \\
\hline Relative Risk & 1.48 & \\
\hline
\end{tabular}

introduction of routine hepatitis B immunization in New Zealand, many additional countries began routine hepatitis B immunization. Italy was the second country with routine hepatitis B immunization however the practice was started in France, Spain, US, Portugal, and many other countries. Data on the incidence of IDDM following routine hepatitis B immunization was available in Italy and France. The current study was performed to determine if data from additional areas where hepatitis B immunization was started supported a causal relationship between the hepatitis $B$ vaccine and IDDM. The finding of a consistent 2-3 year delay between hepatitis $\mathrm{B}$ immunization and a rise in the incidence of IDDM is consistent with a causal relationship and consistent with findings with other common pediatric vaccines [2].

The data indicated that the hepatitis B vaccine was associated with an statistically significant increased risk of IDDM in the Italian birth cohort study as well as the French and New Zealand ecological studies. In the Italian birth cohorts, where children were immunized starting at 3 months of life, a rise in the incidence of IDDM was detected that peaked at a relative risk of 1.53 in the second year of life, between age 2 and 3 (Table 1). This is approximately be- 
tween 21 to 33 months after the vaccine was given. The Hepatitis B vaccine was promoted in France starting in 1994. In France children were immunized both as infants and at school age around 11-13 years of age, newborn immunization was generally reserved for offspring of hepatitis B infected mothers [5]. Immunization rates were only $78 \%$ in adolescents and $36 \%$ for infants in 1997 [11]. A rise in the incidence of IDDM in French children 0-4 (Table 2) started in 1996,24 to 36 months after starting the immunization program, and reached a study peak in 1997, 36 to 48 months after the immunization program started. Presumably most of the children did not receive the hepatitis B vaccine in January of 1994 so the delay between actually receiving the vaccine and the development of IDDM would be several months shorter.

We had previously described a rise in the incidence of IDDM following the massive hepatitis B immunization program in New Zealand which started in 1988 [3, 10] More recent data from New Zealand confirms a rise of IDDM after the introduction of the hepatitis $B$ vaccine [9]. The more recent data shows the incidence of IDDM in children age 014 years old increased from 15.37 cases/100,000 in 19801989 to 22.77 cases/100,000 in 1990-1999 ( $\mathrm{p}=0.0008)$ and in individuals age $0-19$ from 14.87 to 20.12 cases $/ 100,000$ in the same years $(p=0.004)$. The hepatitis $B$ vaccine was started in preschool children living in New Zealand in 1988. The incidence of IDDM in children in New Zealand in 1990, 2 years after immunization, reached a record high at the time. The incidence of IDDM in children under age 15 rose between the intervals of 1985-1989 and 1990-1994 from 13.45 to 22.11 cases/100,000 respectively. The incidence of IDDM in New Zealand from 1990-2000 remained elevated (Table 3). By contrast the incidence of IDDM in children under the age of 15 was relatively stable in the intervals not expected to be affected by the hepatitis $B$ vaccine. The data shows that there was actually a decline, in the incidence of IDDM between the time intervals 1980-1984 and 1985-1989 (17.28 to 13.45 cases/100,000 respectively). There was a small rise in the incidence between 1990-1994 and 19951999 (22.1 to 23.43 cases/100,000 respectively). Thus almost all the rise in the incidence of IDDM between 1980 and 2000 occurred starting within 2 years following the hepatitis $\mathrm{B}$ immunization program.

The finding of a 2-3 year delay between hepatitis B immunization, when given starting in the first year of life, and a rise in the incidence of IDDM data are consistent with data of other vaccines. A large prospective clinical trial showed the hemophilus B vaccine caused clusters of cases of IDDM occurring between 36 to 48 months after vaccination [1]. The pertussis and MMR vaccine were associated with cluster of cases of IDDM occurring 24 to 48 months after immunization [2]. There have been papers published by several different groups of authors which reported clustering of cases of IDDM occurring 2 to 4 years after infection with mumps virus [12-15]. Sultz et al. [12] published epidemiology data that there was a 3 to 4 year delay between mumps epidemics and IDDM epidemics. The authors described a median lag time of 3 years and a mean lag time of 3.8 years between the infection with mumps and the development of IDDM. A group from Finland reported a 2 to 4 year delay between mumps infection and the development of IDDM [13]. The authors also cite two older publications which reportedly contain a similar delay between mumps infection and the development of IDDM [4, 15]. A study in Pittsburgh found rises of IDDM associated with epidemics of varicella infections which occurred 2 to 3 years earlier [16]. Researchers attributed an epidemic of IDDM in Philadelphia to an measles epidemic occurring two years previously [17].

Several studies which have prospectively followed groups of individuals at high risk of IDDM, have reported a mean or median 3 year delay between the appearance of autoantibodies to pancreatic islet cells and the development of IDDM [18, 19]. A group of 765 initially non diabetic siblings of diabetic patients in Finland was prospectively followed for the development of IDDM [18, 20]. Diabetes manifested after a mean time of 3.2 years from the detection of anti islet cell antibodies in those that were initially negative at the beginning of the study [18]. A study prospectively followed German children, at risk for developing diabetes because of family history, from birth for the development of IDDM. Researchers screened blood at birth, 9 months, 2 years, and 5 years. They found that in children who had two autoantibodies by age 2, 50\% developed diabetes by age 5, a median onset of approximately 36 months after detection of autoantibodies [19].

Several studies have followed patients at high risk for IDDM, because they have one or more autoantibodies present at the time of enrollment, for the progression to IDDM. The median or mean progression time is often near 3 to 4 years. A study followed 701 Finnish individuals at high risk for IDDM, mean age of 9.9 years. The median time between the enrollment in the study and the development of IDDM was 3.3 years while the median follow up time for the non progressors was 10.3 years [20]. Almost all of those who were ICA positive at the beginning of the study, and went on to develop diabetes, did so within 5 years. A US study [21] followed 7,834 high risk people (median age 27.4 years) for the development of IDDM, with a median of 4.6 years of follow-up. During the study 135 participants developed IDDM with a median age 10.5 and a median time between the enrollment in the study and the development of IDDM of 2.8 years, similar to the Finnish study above. An group in Italy [22] followed 158 individuals, median age 45, with islet cells antibodies (ICAs) for the development of IDDM. The mean time between the enrollment in the study, ICA positive, and the development of IDDM was 4.8 years.

The interval between hepatitis B immunization and the rise in IDDM was considerably shorter in children immunized after the age of 10 . In Italy the hepatitis B vaccine was given to children at age 12 years old. An increased risk of IDDM was seen at age 12 with a maximum risk seen at age 13,1 to 2 years after immunization (Table 1). Immunization with the Hepatitis B vaccine in those 11 years or older in France was first promoted in 1994. A rise in IDDM was detected in children age 10-14 in 1995. The incidence reached a study peak in 1997, 3 years after immunization (Table 2). These results are consistent with our previous findings with BCG $[2,3]$ and our finding with rises in IDDM shortly after entry into the military [23]. More recently data from the US Department of Defense showed an increased risk of IDDM associated with anthrax immunization. The increased risk was seen within 90 days of immunization and continued after wards [24]. The shorter delay between immunization and 
the increased risk of IDDM in older children can be explained by prior destruction of the islet cells. In cases of IDDM occurring within weeks of immunization IDDM may be caused because the vaccine induces release of interferons which makes the patients less sensitive to insulin making people with borderline IDDM become frank diabetics. In cases of IDDM occurring 8 weeks or more after immunization the vaccine may induce diabetes by accelerating autoimmune destruction in a person who had already had extensive destruction of the islet cells.

An estimate was made of the relative risk of IDDM associated with the hepatitis B vaccine and compared to the relative risk associated with other vaccines. In Italy the combined relative risk for the time intervals studied was 1.4 (Table 1). In children immunized at age 12 , the relative risk was 2.22 between ages 12 through 14 . Immunization rates in this population varied from $30 \%$ to $49 \%$ in the years $1993-1997$. In children ages 2 and 3 years old, who were immunized at age 3 months, the relative risk was 1.53 . Immunization rates in infants varied between $27.4 \%$ to $49.2 \%$ in the years 1993 1996 so the adjusted relative risk exceeds 2. In French children age $0-4$ the relative risk was 1.6 and immunization rates were $36 \%$ for infants in 1997 [11]. The adjusted relative risks in children under 5 exceeds 2 . In French children age 10-14 the relative risk was 1.31 . Immunization rates were $65 \%$ in adolescents age 13-15 [25]. In children age 10-14 the adjusted relative risk would be less than 2 however immunization rate does not apply to children age 10-12 and thus it is likely that in the immunized children aged 13-14 the relative risk also exceeds 2 as it did in Italy. In New Zealand the relative risk in children age $0-14$ was 1.48 (Table 3 ). This would also be compatible with a relative risk of greater than 2 between 12 to 48 months after immunization. The relative risks are comparable to what is seen with the pertussis, MMR, and $\mathrm{BCG}$ vaccine [2]. The relative risks are under 2 over a 10 year period but exceed 2 in clusters spanning 24 to 48 months after immunization. These relative risks are higher than those seen with an early Hemophilus vaccine [1] where the relative risk exceeds 2 in 6-8 month clusters occurring between 36-48 months after immunization.

Willis and Scott, have repeatedly questioned [9] our published association [10] between the hepatitis $b$ vaccine and the development of IDDM in New Zealand. They continue to cite a study which is severely flawed. In their study [26] they compared the incidence of IDDM in children born before February 1988 to the incidence in children born after this time. They concluded the data does not support an association between Hepatitis B immunization and IDDM. The analysis is flawed for two reasons. First it assumes those born prior to 1988 did not receive hepatitis B vaccine. In fact there was a massive catch-up program in New Zealand and while the hepatitis B vaccine was initially given to all preschool children [7] the immunization program was soon expanded so that all the children under the age of 16 received the hepatitis B vaccine, not just those born after 1988. The acceptance rates were estimated to be above 70\% (Personal communications, Dr. Harry Nicholls, Senior Advisor for Communicable Diseases, Ministry of Health, Wellington, NZ). Children born in the 1970s and early 1980s therefore received the hepatitis $B$ vaccine. A second problem with the analysis is that the incidence of IDDM differs depending on the age of the child in most countries including New Zea-

land, with fewer cases of IDDM occurring in ages 1-5 versus 10-14 [8]. Willis' analysis only demonstrates that the incidence of IDDM is higher in older children, those born before 1988, than the very young children, those born after 1988 .

Karen Poutasi, the Minister of Health in New Zealand, has also published two letters $[27,28]$ trying to refute an association between the hepatitis $B$ vaccine and a rise in the incidence of IDDM in the South Island of New Zealand, Canterbury $[10,29]$. She stated a reason for believing that the hepatitis B vaccine does not cause IDDM "The Auckland registry (North Island) did not exhibit any epidemic increase after December 1989 when hepatitis immunization was recommended at age 6 weeks [28]. She states "Classen fails to explain why the Auckland diabetes registry did not show any increase following the introduction of the Hepatitis B vaccine." However a later publication from New Zealand admitted a rise in IDDM did occur in the North Island after hepatitis B immunization began [30].

A US government funded case control study [31] was conducted to confirm the association between the hepatitis B vaccine and IDDM which was discovered in New Zealand. The preliminary data found an odds ratio of 1.9 when the hepatitis B vaccine was given starting after two months, the average follow up was 22 months. A later analysis claims that immunization starting after 8 weeks of life was not associated with an increased risk of IDDM [32]. Approximately $75 \%$ of cases and controls were less than 6 years of age indicated that there should have been at least 3 or more years of follow up after immunization to detect the cases of vaccine induced IDDM. There was no indication that there was adequate follow up to detect cases of vaccine induced IDDM. Another problem with the study is that there was no attempt to control for the effect of confounding vaccines. The effect of the hepatitis $B$ vaccine could be hidden by an effect of other vaccines such as the hemophilus vaccines if children who did not receive the hepatitis $B$ vaccine were more likely to receive immunization with the hemophilus or other vaccines.

A pattern is arising that vaccines are consistently associated with an clinically significant rise in IDDM [1-3]. A recent publication reviewed the potential mechanisms of vaccine induced IDDM [33] and additional data supporting the role of macrophages was reviewed in a follow up paper [2] which includes the role of activated macrophages in islet cell destruction following transplantation. Research from France has substantiated the pathological activation of macrophages by aluminum containing vaccines including the hepatitis B vaccine and linked the activation of the macrophages to chronic immune mediated diseases including autoimmune diseases [34]. Interestingly in the French studies the mean delay between immunization and the biopsy demonstrated diagnosis of the macrophage induced disease was 36 months.

\section{CONCLUSION}

IDDM is a common autoimmune disorder and immune stimulation with a variety of immune stimulants has been associated with a rise in autoimmunity in both animals and humans. It is thus predictable that when you immunize a large population of children you would measure a significant increased risk for IDDM. In groups where the risk of hepatitis B is high and the risk of IDDM is low, current immuniza- 
tion practices may be beneficial to the health of the population when only considering the risk of IDDM. However, IDDM is only one autoimmune disease that can be induced by the hepatitis $\mathrm{B}$ vaccine. In populations where the risk of hepatitis B is only moderate and the risk of IDDM is high, such as most Northern European and North American populations, ways of giving the hepatitis B vaccine with out inducing IDDM needs to be employed. One potential mechanism of immunization which may actually lower the risk of IDDM is to give the vaccine starting in the first month of life. This method has been associated with a decreased risk of IDDM in both humans [3,35] and animals [36].

\section{DISCLAIMER}

The author is president and stock holder of Classen Immunotherapies, Inc. which holds patents on methods of testing vaccines for causing autoimmunity and methods of administering vaccines to prevent vaccine induced autoimmunity.

\section{REFERENCES}

[1] Classen JB, Classen DC. Clustering of cases of insulin dependent diabetes (IDDM) occurring three years after Hemophilus influenza B (HiB) immunization support causal relationship between immunization and IDDM. Autoimmunity 2002; 35: 247-53.

[2] Classen JB, Classen DC. Clustering of cases of IDDM occurring 24 years after vaccination is consistent with clustering after infections and progression to IDDM in autoantibody positive individuals. J Pediatr Endocrinol Metab 2003; 16 (4): 495-507.

[3] Classen DC, Classen JB. The timing of pediatric immunization and the risk of insulin-dependent diabetes mellitus. Infect Dis Clin Pract 1997; 6: 449-54.

[4] Sebastiani L, Visalli N, Adorisio E, et al. A 5-year (1989-1993) prospective study on the incidence of IDDM in Rome and the Lazio region in the age group 0-14 years. Diabetes Care 1996; 1996: 70-3.

[5] Merle P, Trepo C. [-Vaccination against hepatitis B-.]. Arch Pediatr Adolesc Med 1998; 5: 326-32.

[6] Charkaluk MR, Czernichow P, Levy-Marchal C. Incidence data of childhood-onset type 1 diabetes in France during 1988-1997: the case for a shift toward younger age at onset. Pediatr Res 2002; 52: $859-62$.

[7] Gunn T. N Z Med J 1989; 102: 2-3.

[8] Scott R, Brown LJ, Darlow BA, Forbes LV, Moore MP. Temporal variation in incidence of IDDM in Canterbury, New Zealand. Diabetes Care 1992; 15: 895-9.

[9] Willis JA, Scott RS, Darlow BA, et al. Incidence of type 1 diabetes mellitus diagnosed before age 20 years in Canterbury, New Zealand over the last 30 years. J Pediatr Endocrinol Metab 2002; 15: $637-43$.

[10] Classen JB. Diabetes epidemic follows hepatitis B immunization program. N Z Med J 1996; 109: 195.

[11] Begue P. [Vaccination calendar and new risks of infection]. Ann Med Int (Paris) 1998; 149: 379-84.

[12] Sultz HA, Hart BA, Zielezny M. Is the mumps virus an etiologic factor in juvenile diabetes mellitus. J Pediatr 1975; 86: 654-6.

[13] Hyoty H, Leinikki P, Reunanen A, et al. Mumps infections in the etiology of type 1 (insulin-dependent) diabetes. Diabetes Res 1988; 9: 111-6.
[14] Melin K. Diabetes as complication of parotitis epidemica. Nord Med 1958; 27: 1715-7.

[15] Gundersen E. Is diabetes of an infectious origin. J Infect Dis 1924; 41: 197-202.

[16] Dokheel TM. An epidemic of childhood diabetes in the United States. Diabetes Care 1993; 16: 1606-11.

[17] Lipman TH, Chang Y, Murphy KM. The epidemiology of type 1 diabetes in children in Philadelphia 1990-1994. Diabetes Care 2002; 25: 1969-75.

[18] Karjalainen J, Vahasalo P, Knip M, Tuomilehto-Wolf E, Virtala E, Akerblom HK. Islet cell autoimmunity and progression to insulindependent diabetes mellitus in genetically high and low siblings of diabetic children. Eur J Clin Invest 1996; 26: 640-9.

[19] Zeigler AG, Hummel M, Schenker M, Bonifacio E. Autoantibody appearance and risk for development of childhood diabetes in offspring of parents with type I diabetes: the 2 year analysis of the German BABYDIAB study. Diabetes 1999; 48: 460-8.

[20] Kulmala P, Savola K, Reijonen H, et al. Genetic markers, humoral autoimmunity, and prediction of type 1 diabetes in siblings of affected children. Diabetes 2000; 49: 48-58.

[21] Maclaren N, Lan M, Coutant R, et al. Only multiple autoantibodies to islet cells (ICA), insulin, GAD65, IA-2, and IA2B predict immune-mediated type 1 diabetes in relatives. J Autoimmun 1999; 12: 279-87.

[22] Bosi E, Becker F, Bonifacio E, et al. Progression to type 1 diabetes in autoimmune endocrine patients with islet cell antibodies. Diabetes 1991; 40: 977-84.

[23] Classen JB, Classen DC. The safety of military immunization and the risk of insulin dependent diabetes. Clin Pract Altern Med 2001; 2: $247-52$.

[24] Joellenbeck LM, Zwanziger LL, Durch IS, Strom BL, Eds. The Anthrax Vaccine. Is It Safe? Does It Work? Washington DC: National Academy Press, 2002; 118-179.

[25] Goudeau A, Denis F. Bull Soc Pathol Exot 1998; 91: 41.

[26] Willis J, Scott R, Darlow B, Lunt H, Moore P. Hepatitis B immunisation and the epidemiology of IDDM in children and adolescents aged $<20$ years in Canterbury New Zealand. Diabetes 1997; 46(Suppl 1): 140A.

[27] Poutasi K. Immunisation and diabetes. N Z Med J 1996; 109: 283.

[28] Poutasi K. Immunization and diabetes. N Z Med J 1996; 109: 3889.

[29] Classen JB. The diabetes epidemic and the hepatitis B vaccine. N Z Med J 1996; 109: 366

[30] Petousis-Harris H, Turner N. Hepatitis B vaccination and diabetes. N Z Med J 1999; 112: 303-4.

[31] DeStefano F, Okoro C, Graffander P, Chen RT. The timing of hepatitis B immunization and risk of insulin dependent diabetes mellitus. Pharmacoepidemiol Drug Saf 1997; 6 S2: S60.

[32] DeStefano F, Mullooly JP, Okoro CA, et al. Childhood vaccinations, vaccination timing, and risk of type 1 diabetes mellitus. Pediatrics 2001; 108: e112.

[33] Classen JB, Classen DC. Vaccines and the risk of insulin dependent diabetes (IDDM), potential mechanism of action. Med Hypotheses 2001; 57: 532-8.

[34] Gherardi RK, Coquet M, Cherin P, et al. Macrophage myofasciitis lesions asses long-term persistence of vaccine-derived aluminium hydroxide in muscle. Brain 2001; 124: 1821-31.

[35] Classen JB, Classen DC. Immunization in the first month of life may explain decline in incidence of IDDM in the Netherlands. Autoimmunity 1999; 31: 43-5.

[36] Classen JB. The timing of immunization affects the development of diabetes in rodents. Autoimmunity 1996; 24: 137-45. 